\title{
How COVID-19 Pandemic Impacted General Population, Diagnostic Facilities and Frontline Warriors
}

\author{
Anjali Katkar and Sarika Dakhode \\ Jawaharlal Nehru Medical College, Datta Meghe Institute of Medical \\ Sciences, Wardha, Maharashtra, India \\ Corresponding author email: sumanharidaskatkar@gmail.com
}

\section{ABSTRACT}

COVID-19 or coronavirus disease - 2019 as named by World Health Organization has grappled the world since first case emerged from wet market of Wuhan in Hubei province, People's Republic of China. From the morphology of the virus which is crown in shape it is named so as coronavirus .From that day to now every aspect of human life is affected by the pandemic which was declared as it is by WHO in mid-march. Globalizations and inter-connectedness has been key factor in spreading the disease and transforming from outbreak to epidemic to pandemic which is severe than Spanish flu of 1918. Many countries-imposed lockdowns which are almost confining peoples to their homes resulting massive traffic on social networking sites forwarding the unverified and, in some cases, dangerous claims. So there is a need of counter information campaign to aware, educate the masses about the pandemic with authentic and tested information which will not only help people but also authorities to concentrate their focus on the pandemic and most awaited vaccine. The psychological impact on health professionals and other front line workers is must to study as these are the important arsenals to fight the exponentially growing pandemic. Meanwhile some anti-social activities against doctors such as evictions from societies, attacks etc. created more havoc and panic among the warriors. Every citizen is benefitting from the COVID-19 warriors whether at home or at hospitals. COVID-19 warriors need to be thanked for their eternal service to humanity. This article reflects on the related aspects of impact of COVID-19 on general population , healthcare facilities and frontline warriors.

KEY WORDS: FRONTLINE WARRIORS, COVID-19, RT-PCR , INFODEMIC, IMPACT, DIAGNOSTIC FACILITIES.

\section{INTRODUCTION}

There are an estimated 10 to the power 31 number of virus present on Earth. Fortunately or unfortunately only one is wreaking havoc around the globe. COVID-19 or coronavirus disease - 2019 as named by World Health Organization has grappled the world since first case emerged from wet market of Wuhan in Hubei province , People's Republic of China. From the morphology of the virus which is crown in shape it is named so as

Biosc Biotech Res Comm P-ISSN: 0974-6455 E-ISSN: 2321-4007

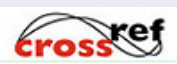

Identifiers and Pagination

Year: 2021 Vol: 14 No (6) Special Issue

Pages: 225-230

This is an open access article under Creative

Commons License Attribn 4.0 Intl (CC-BY).

DOI: http://dx.doi.org/10.21786/bbrc/14.6.47 coronavirus .From that day to now every aspect of human life is affected by the pandemic which was declared as it is by WHO in mid-march. Globalizations and interconnectedness has been key factor in spreading the disease and transforming from outbreak to epidemic to pandemic which is severe than Spanish flu of 1918 (Pulido CM,et al 2020).

The virus itself undergone lot of changes in its genomic sequence and after effects consequently changing the symptoms gradually. From cough, cold to fever, diarrhea etc. researchers are still studying the strain (Guan W, et al 2020). Although the race for vaccine development has begun but naturally it will take time as it is a multilevel process. Further reinfection cases detected has been closely monitored so that firm conclusion to draw future course of action. WHO constantly collecting information from various countries which can be analyzed to counter it. Problem of INFODEMIC is also a fear factor along

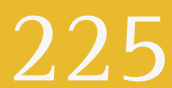


with the pandemic which can be managed with utmost precautionary measures and counter information strategy. Geography, Climatic conditions also has an impact on number of cases and types of cases. High density residential clusters are more exposed than low density and sparsely populated communities. Further serological surveys confirming the trend of large population exposure to the above-mentioned disease and production of antibodies. For detection the types of tests also matter as RT-PCR is best known but has some flaws and antibody test which needs further confirmation and is used in finding the spread between communities.

The study on whether or not to print the Cycle threshold value on the patients report should be done with proper evidence suggesting some correlation between the shedding capacity of viral load and the CT value. The most neglected aspect of the human resource of the health care professionals is their psychological status. Most are working in stressful situations where they have to give their best, keep themselves protected and cautious of being infect the family members.

Re-infection or recurrences among COVID-19 Patients: In the earlier phase of the COVID-19 pandemic the fear of persisting the infection or re-infection was detected but later found in anti-bodies test which suggests that in all cases the dead strain of the virus was giving the test positive and it was just the matter of time for disappearing the virus strain from the body. RT-PCR (Reverse transcription polymerase chain reaction) test is the final and ultimate test to confirm any strain.

But recent reports from various countries registering confirmed reinfection cases some of which unaware and living in false sense of security only to be caught by random testing by authorities. There are certain similarities and differences reported although data on the patient with their due consent and condition of anonymity is not enough to derive any conclusion (Gousseff M, et al 2020). One of the first confirmed case of reinfection of COVID-19 was reported in Hong Kong.One of the infections was detected in march and recent one in august. This clear put question mark on our efforts to contain the pandemic and the immunity developed in recovered patients. Although the patient was asymptomatic and had no symptoms. On the other hand, the case from Nevada, USA was showing symptoms such as hypoxia, myalgia, cough and shortness of breath and required oxygen support system. It is premature to categorize the patients but scientists were expecting such behavior of virus as was the case with SARS and MERS outbreak.

In India too there are some cases reporting supposedly on reinfection. A 27-year-old woman had tested positive for coronavirus nearly 30 days after she was first discharged from the hospital. This is the first confirmed case of COVID-19 reinfection in Bengaluru (Yasmeen A. 2020). Recently a doctor from Dehradun in Himalayan state of Uttarakhand has been tested positive in rapid antigen test though study results of genomic strain is pending. There are lots of possibilities that are being checked. First there could be lack of anti-bodies developed in the patient and viral load is slipped in lungs making it difficult to catch in swab test resulting in non-elimination of disease at first place. In addition the methods employed by the swab collector staff is not foolproof as it contains lots of improper methods. It is seen that swab collectors sometimes collects the swab from nasal cavity, sometimes collects from inner parts. It severely influences the results as the viral can vary according to the position of swab, where it had been taken. Second reason might attributed to the different viral strain from which it was first infected. In the case of Hong Kong patient the genomic study suggested the new type of viral strain that infected the person. As the history of the virus suggests that they mutate after certain interval of time.

This topic of reinfection has brought the question mark on the efficacy of the vaccines under development. But scientist suggests that reinfection is common in coronavirus family and other seasonal viruses. Therefore incidences of reinfection is not causing panic among scientific and health sector fraternity. Thankfully the vaccine candidate which are underdevelopment are so designed to counter different strains of viruses. But to counter all the strains of the virus present in the world there must be a repository where the genome sequencing of every virus is present. So that more effective and comprehensive vaccine can be made. Still more study is needed as this virus is unfolding and unleashing new factors every day to study. Though in their case the protection offered was one and half to two years. Again COVID-19 reinfection should be differentiated from persistence traces of RNA which is present and detected even after few weeks post recovery (Roy S. 2020).

Additional challenge of mis-information during COVID19 pandemic: As the whole world is fighting the COVID-19 pandemic there is another lesser noticed but doing more harm is the challenge of mis-information. As the World Health Organization termed it as INFODEMIC. Which is the combination of information and pandemic. It is the form of information in this post information revolution era where internet connectivity and penetration areexpanding its roots deeper which misguides the people about the pandemic which still lesser known. From native medicines and herbal alternatives to consuming sanitizers strictly meant for external use only the mis information is only aggravating the already worsening conditions. The mouth publicity of certain medicines, the un prescribed use of drugs can severely hamper the efforts to flatten the curve of COVID-19.In addition the rumor mongering on social media which on one click goes viral these days and can make or break the situation should be handled at war footing. COVID-19 containment strategy is already consuming maximum resources available at the disposal of the authorities. the very small is available to deal with other issues so INFODEMIC would certainly add to the woes.

Many countries-imposed lockdowns which are almost confining peoples to their homes resulting massive traffic 
on social networking sites forwarding the unverified and, in some cases, dangerous claims. So there is a need of counter information campaign to aware, educate the masses about the pandemic with authentic and tested information which will not only help people but also authorities to concentrate their focus on the pandemic and most awaited vaccine (Dushyant Bawiskar, et al 2020).

In addition the daily news on vaccine development can misguide the public and the masses as they can think that the phases are complete and vaccine next door so resulting in more unsafe people to people interaction without following the physical distancing guidelines. The hoax about particular type of cattle driven food can cause COVID-19 have cascading effects be it economically, nutritionally or socially. The drastic and sudden change in regular diet due to misinformation on particular type of food can also create huge disaster. Already the resources are diverted very much towards the Containment of COVID-19, therefore any other disease outbreak due to sudden change in diet will only add to the long list of problems already existing. Also doubting the health authorities and suspecting them of falsely admitting patient in hospital which is going viral is seriously a cause of concern. First of all it is based upon rumors created by some anti-social elements to create social disharmony. This can cause under reporting of cases and increase in number of cases.

Is RT-PCR test enough?: Absolute certainty is unattainable no matter what efforts we put in. We try to minimize the errors and try to reach the diagnosis which is correct. After the pandemic started spreading its tentacles, the main question before authorities, doctors and scientists was how to successfully identify the patients suffering from COVID-19. The best known till now is RT-PCR test which is being carried out all over world. But it is seen that in some positive cases, they were not detected by RT-PCR test on which the doctors and scientists rely upon. It primarily uses nasal swabs. In some cases, the viral load was shifted towards lungs becoming difficult to detect the virus. Other test widely used is antibodies test which works on blood samples. But it shows weeks after formation of antibodies and it makes it difficult to draw immediate conclusion. It is widely used in checking prevalence of the disease in a particular area. The serological surveys implying that large number of people got the virus and they never knew. It was due to strong immune response generated by the body and the less virulence of the virus after considerable amount of time has been passed.

False negatives can be headache as this can generate the false sense of security among the suspected candidate. Recently some researchers at University of Cambridge developed point-of-care test which combines the two kinds of the above-mentioned tests. The researchers found that only RT-PCR test was able to find 8-9 out of 10 cases while the point-of-care test was able to confirm $100 \%$ of cases that was tested. It is yet to spread out its reach globally. The debate on cycle threshold (Ct) value on whether it creates a difference or not. Basically Cycle threshold value is the value of number of cycle performed by the the test to uncover or magnify the virus. It supposedly suggests that the lower the number of ct value the higher the person can shed the virus. On the contrary the higher number implies low shedding power of the candidate. But serious doubts are raised whether this parameter to be used in strategizing the CIVID-19 containment strategy. We have to take into account the co-morbidities the person is having. The person having high ct value and comorbidity cannot live in fool's paradise of not having the disease. Therefore there must be a proper study to correlate the ct value and shedding capacity of viral load. Till then there is no need to display ct value on patients report as it can create the false sense of security (Clark TW, et al 2020).

Mortality Rate Then vs now: As of September 2020 there are around 30 million cases around the world. The deaths reported due to COVID-19 is at one million. And there is no sign of peak arrived yet. At this juncture, five months after the virus first struck, mortality rate is seen widely as success rate in containing the pandemic. Changing epicenter from china to Europe and now Americas, the mortality is on decline even after record number of daily cases registering. This is due to the fact that many countries are easing their lockdown restrictions and festive season is round the corners. Low mortality rate is attributed to the weakened virulence of the virus as was seen in past in swine flu outbreak. Initially cases with severe symptoms were reported more than milder ones.

But now more milder cases are reporting of which little percentage of cases requires oxygen support system. Another reasons include late use of repurposed drugs such as Remdesivir , Lopinavir etc. which was not known to be effective initially. The trend of country having low mortality rate with universal Bacillus Calmette Guerin (BCG) vaccine immunization is interesting to see. Especially in south Asia where cases and mortality rate is low despite extreme density of the population. In India which is about to become most populous country in the world having the 1.3 billion people of total of 7 billion people present on earth shows remarkably low mortality rate of around $1.7 \%$. Though another reason can be harshest lock down as part of non-pharmacological interventions (NPI's) imposed.

The choice between containment of diseases and reducing the mortality rate is difficult. As first involves lots of allied issues of education and non-covid-19 health services. The second purely focuses on the reduction of the mortality rate. That implies whether people contracting the disease is not a problem but curing them is must. This can be contradictory. The question of choice between lives and livelihood in low income countries also complicates the situation. Proper information about symptoms and change in the same conveyed by World Health Organization and other local authorities was beneficial as people were taking precaution and reporting early at the health care center if any symptom is found. 
In addition, various serological surveys conducted in various cities with high prevalence of COVID-19 indicated that around quarter of the population have antibodies in their blood culture (Palem SP, Palem HP 2020).

Emotional Perspective of frontline warriors: "The true Warrior fights not because he hates what is in front of him, but because he loves what is behind him."

A perfect saying for what our heroes are doing be it a health care professionals, police authorities, and many others who are fighting the unprecedented pandemic of COVID-19 to protect people like ourselves from the deadly virus. Long before mid-march when World Health Organization declared the COVID-19 disease as pandemic the COVID-19 warriors were already taken their guards up to fight and urging people to co-operate. Even in the lockdown where people were confined in their homes feeling safe and relaxed for a bit, the warriors were on the move to fight the unforeseen situation. Health care professionals in hospitals, police authorities on ground even the most neglected professions of ambulance drivers and Asha workers were risking their lives to contain and mitigate the virus spread. They often get less coverage than expected resulting in apathy towards them in common people. Their role is grossly underestimated by public which was felt during the pandemic.

Frontline warriors fighting on two fronts making it more difficult for them to dispense their duties but they promptly overcome this due to extreme willingness to serve the people. At field where doctors, nurses and other health workers and police and field workers frisking the people roaming without valid reasons are extremely prone to catching the disease. In addition the constant tension in their mind of "what if my family members catches the virus from me?". This duopoly takes huge toll on their minds resulting into stress and anxiety. Plus the dosage of preventive medicines such as HCQ which generates lot of heat is another not so good consequence. The shift of the doctor or nurse requires at least 12 hours a day wearing the personal protective equipment (PPE) kit in which you can't even go for dispatching the waste material from the body. Even in these harsh condition our COVID-19 warriors are fighting with conviction and hopes to eliminate the virus with the same vigor (Dubey S, et al 2020 and Guo J,et al 2020).

The fear of contracting the virus to family members resulting into estrangement between them taxing them emotionally. In this tough scenario they need at least some mental support and assurance that things are going to be okay. The emotional toll is made much worse when many of these health works are themselves in isolation, away from their families, in order only to protect them from potential risks. (Somashekahar et. al. 2020) reviewed the ASI's Consensus Guidelines to be followed in Covid 19. (Spoorthy et. al 2020) have reviewed about mental health problems faced by healthcare workers due to the Covid-19 pandemic. Risk factors of respiratory health issues in this region are evident from the previous studies (Taksande, et al 2016, Dhar, et al 2019, Salampuria, et al 2019 and Dhar, R., et al 2017). A number of reviews reflected on different aspects of COVID-19 and it's impact on population (Deshpande, M.A., et al 2020, Gulrandhe, P., et al 2020 and Jachak, S., et al 2020) and medical fraternity (Gaidhane, S., et al 2020, Anjankar, V.P., et al 2020 and Ghate, V.C., et al 2020). (Bawiskar et.al 2020) reported about haematological Manifestations of Covid19. (Godhiwala et.al. 2021) reported about leukemoid reaction in a COVID-19. (Gupta et.al. 2020) discussed on use of nitrous oxide-oxygen inhalation sedation in the COVID-19 Era. (Hande et.al. 2021) suggested modalities to restrain the progression of oral potentially malignant diseases patients in Covid-19.

Meanwhile some anti-social activities against doctors such as evictions from societies, attacks etc. creates more havoc and panic among the warriors. We as an evolving society should think about such acts and these elements should be defenestrate from the society. Finally, every citizen is benefitting from the COVID-19 warriors whether at home or at hospitals, should thank the COVID-19 warriors near them for their eternal service to humanity. This acknowledging and simple gesture will boost up their morale and make them more confident than before.

\section{CONCLUSION}

In this stage of the pandemic the clinical recurrences should be studied with proper empirical data as it has just started to showing up. Densely populated regions of the world should plan effective containment strategy as lockdown in various countries are easing up. Further mortality rate which is widely seen as success rate in containing the pandemic must be analyzed thoroughly so that most vulnerable can be identified and the mortality rate goes down further. The choice between lives and livelihood has to be made locally as according to circumstances. The stressed health workforce should be treated in a gentle way and necessary support be it mental or physical be provided. Sensitization of masses for the plight of all the health care workers be it doctor or the paramedic's staff. The debate on cycle threshold (CT) value should be stopped as soon as possible ass there no empirical data suggesting the relation between the shedding capacity of the person of the viral load and the value of the cycle threshold (CT) value to avoid confusion among the masses. INFODEMIC can be treated by counter campaigning with correct and authentic information. As the process of vaccine development is progressing day by day authorities must be ready with plan about how to administer the vaccine starting from most vulnerable groups.

\section{REFERENCES}

Anjankar, V.P., Anjankar, A.P. and Anjankar, A.J., 2020. Review of the Impact of COVID-19 on Medical Education System. Int J Cur Res Rev| Vol, 12(20), p.183.

Bawiskar, D., Phansopkar, P. and Gotmare, A.V., 2020. Covid-19 facets: Pandemics, curse and humanity. 
International Journal of Research in Pharmaceutical Sciences, 11(Special Issue 1).

Bawiskar, N., Andhale, A., Hulkoti, V., Acharya, S. and Shukla, S., 2020. Haematological Manifestations of Covid-19 and Emerging Immunohaematological Therapeutic Strategies. Journal of Evolution of Medical and Dental Sciences, 9(46), pp.3489-3495.

Clark, T.W., Brendish, N.J., Poole, S., Naidu, V.V., Mansbridge, C., Norton, N., Wheeler, H., Presland, L. and Ewings, S., 2020. Diagnostic accuracy of the FebriDx host response point-of-care test in patients hospitalised with suspected COVID-19. Journal of Infection, 81(4), pp.607-613.

Dhar, R., Singh, S., Talwar, D., Mohan, M., Tripathi, S.K., Swarnakar, R., Trivedi, S., Rajagopala, S., D’Souza, G., Padmanabhan, A. and Baburao, A., 2019. Bronchiectasis in India: results from the European multicentre bronchiectasis audit and research collaboration (EMBARC) and respiratory research network of India registry. The Lancet Global Health, 7(9), pp.e1269e1279.

Deshpande, M.A. and Deshpande, A.M., 2020. Preventive measures for COVID 19 through dincharya and rutucharya mentioned in ayurvedic text. International Journal of Research in Pharmaceutical Sciences, 11(Special Issue 1).

Dhar, R., Mohan, M., D’souza, G., Rajagopalan, S., Singh, V., Jindal, A., Ghewade, B., Joshi, G., Sahasrabuddhe, T., Gami, S. and Nair, G., 2017. Phenotype characterization of non cystic fibrosis bronchiectasis in India: baseline data from an Indian bronchiectasis registry. In B 103. CLINICAL STUDIES IN BRONCHIECTASIS, IMMUNODEFICIENCY, AND DRUG INDUCED LUNG DISEASE (pp. A4726-A4726). American Thoracic Society.

Dubey, S., Biswas, P., Ghosh, R., Chatterjee, S., Dubey, M.J., Chatterjee, S., Lahiri, D. and Lavie, C.J., 2020. Psychosocial impact of COVID-19. Diabetes \& Metabolic Syndrome: Clinical Research \& Reviews, 14(5), pp.779788.

Gaidhane, S., Khatib, N., Zahiruddin, Q.S., Gaidhane, A., Telrandhe, S. and Godhiwal, P., 2020. Depression, anxiety and stress among the general population in the time of COVID-19 lockdown: A cross-sectional study protocol. International Journal of Research in Pharmaceutical Sciences, 11(Special Issue 1).

Gousseff, M., Penot, P., Gallay, L., Batisse, D., Benech, N., Bouiller, K., Collarino, R., Conrad, A., Slama, D., Joseph, C. and Lemaignen, A., 2020. Clinical recurrences of COVID-19 symptoms after recovery: viral relapse, reinfection or inflammatory rebound?. Journal of Infection, 81(5), pp.816-846.

Guan, W.J., Liang, W.H., Zhao, Y., Liang, H.R., Chen,
Z.S., Li, Y.M., Liu, X.Q., Chen, R.C., Tang, C.L., Wang, T. and Ou, C.Q., 2020. Comorbidity and its impact on 1590 patients with COVID-19 in China: a nationwide analysis. European Respiratory Journal, 55(5).

Gulrandhe, P., Sahu, A., Dandale, C., Naqvi, W.M., Phansopkar, P. and Kumar, K., 2020. Repercussions of mass gathering: Covid-19 pandemic. International Journal of Research in Pharmaceutical Sciences, 11(Special Issue 1).

Guo, J., Liao, L., Wang, B., Li, X., Guo, L., Tong, Z., Guan, Q., Zhou, M., Wu, Y., Zhang, J. and Gu, Y., 2020. Psychological effects of COVID-19 on hospital staff: a national cross-sectional survey of China mainland. Available at SSRN 3550050.

Gupta, K., Emmanouil, D. and Sethi, A., 2021. Use of nitrous oxide-oxygen inhalation sedation in the COVID-19 era. International Journal of Paediatric Dentistry, 31(3), pp.433-435.

Hande, A., Sonone, A., Gadbail, A., Gawande, M., Patil, S. and Sharma, P., 2020. Modalities to restrain the progression of oral potentially malignant diseases and oral squamous cell carcinoma in COVID-19 pandemic. Oral Oncology.

Jachak, S., Phansopkar, P. and Naqvi, M.W., 2020. Impact of covid-19 in India, a disastrous pandemic outbreak. International Journal of Research in Pharmaceutical Sciences, 11(Special Issue 1).

Latchoumi, T.P., Ezhilarasi, T.P. and Balamurugan, K., 2019. Bio-inspired weighed quantum particle swarm optimization and smooth support vector machine ensembles for identification of abnormalities in medical data. SN Applied Sciences, 1(10), pp.1-10.

Palem, S.P. and Palem, H.P., 2020. The effect of COVID-19 on global population and its fatality rate: Retrospective study by online database. Indian Journal of Medical Sciences, 72(1), p.13.

Pulido, C.M., Villarejo-Carballido, B., Redondo-Sama, G. and Gómez, A., 2020. COVID-19 infodemic: More retweets for science-based information on coronavirus than for false information. International Sociology, 35(4), pp.377-392.

Roy, S., 2020. COVID-19 reinfection: myth or truth?. SN Comprehensive Clinical Medicine, 2(6), pp.710-713.

Salampuria, S., Jajoo, S. and Acharya, S., 2019. Acute respiratory distress syndrome during pregnancy and post-partum-a case series with spectrum of near miss to mortality. Journal of Evolution of Medical and Dental Sciences-JEMDS, 8, pp.3724-26.

Schmid, M.B., Fontijn, J., Ochsenbein-Kölble, N., Berger, C. and Bassler, D., 2020. COVID-19 in pregnant women. The Lancet Infectious Diseases, 20(6), p.653.

Somashekhar, S.P., Shivaram, H.V., Abhaham, S.J., Dalvi, A., Kumar, A., Gode, D., Misra, S., Jain, S.K., Prasad, 
C.R.K. and Pillarisetti, R.R., 2020. ASI's consensus guidelines: $\mathrm{ABCs}$ of what to do and what not during the COVID-19 pandemic.

Spoorthy, M.S., Pratapa, S.K. and Mahant, S., 2020. Mental health problems faced by healthcare workers due to the COVID-19 pandemic-A review. Asian journal of psychiatry, 51, p.102119

Tarekegn, K., Ramos, A.C., Gross, H.G.S., Yu, M. and Fulger, I., 2021. Leukemoid Reaction in a Patient With Severe COVID-19 Infection. Cureus, 13(2).
Taksande, A.M. and Yeole, M., 2016. Risk factors of Acute Respiratory Infection (ARI) in under-fives in a rural hospital of Central India. Journal of Pediatric and Neonatal Individualized Medicine (JPNIM), 5(1), pp.e050105-e050105

Yasmeen A. 2020. Bengaluru reports 'first' case of COVID-19 reinfection. The Hindu [Internet]. [cited 2020 Sep 11]; Available from: https://www.thehindu.com/ news/national/karnataka/bengaluru-reports-first-caseof-covid-19-reinfection/article32532841.ece 